\title{
AVALIAÇÃO DA PERCEPÇÃO DE DISCENTES E DOCENTES SOBRE NOVAS TECNOLOGIAS DE ENSINO EM CURSOS DE GRADUAÇÃO EM ADMINISTRAÇÃO
}

\author{
ASSESSING THE PERCEPTION OF TEACHERS AND \\ STUDENTS REGARDING NEW TEACHING TECHNOLOGIES IN \\ UNDERGRADUATE MANAGEMENT COURSES
}

Recebido em: 02/08/2013 - Aprovado em: $14 / 10 / 2013$
Avaliado pelo sistema double blind review
Editora Científica: Manolita Correia Lima

\section{FÁBIO PIMENTA DE PÁDUAJÚNIOR pimenta70@gmail.com JOÃO PEREIRA DE CASTILHO FILHO PEDRO JOSÉ STEINER NETO}

\section{ZAKI AKEL SOBRINHO}

UNIVERSIDADE FEDERAL DO PARANÁ

\begin{abstract}
RESUMO
O presente artigo tem por objetivo avaliar os aspectos positivos e negativos de uma possível adoção de novas tecnologias e metodologias aplicáveis aos sistemas de ensino da Administração, tais como: PBL (Problem-Based Learning), EAD (Educação à distância), bem como novos sistemas de avaliação, levando em conta o impacto que as mesmas podem causar no desempenho dos alunos de graduação dos cursos de Administração. Para tanto, foram realizadas doze entrevistas em profundidade com alunos e professores. Os resultados indicam que o uso do PBL é visto com desconfiança e restrição por parte dos alunos, ao passo que os professores acreditam que esta metodologia seja um instrumento que auxilia na transformação do aluno. O uso da EAD também é visto com cautela por ambas as partes, devido ao preconceito ainda existente nesta modalidade de ensino. Entretanto, os entrevistados concordam que o mesmo tem papel fundamental como instrumento auxiliar ao ensino. As inovações no ensino da Administração passam pela maior autonomia do aluno e por projetos multidisciplinares, os quais possibilitam uma visão mais geral, não se restringindo à disciplina. Por fim, constatou-se que as formas de avaliação comumente praticadas pelos professores precisam ser revistas, havendo uma preferência pelo uso de formas mistas que levem em consideração aspectos particulares dos alunos.
\end{abstract}

Palavras chave: inovação no ensino; aprendizagem baseada em problemas; educação à distância; sistemas de avaliação; tecnologia de informação e comunicação.

\footnotetext{
ABSTRACT

This paper aims to evaluate the pros and cons of a possible adoption of new teaching system technologies and methodologies applicable to management, such as PBL, distance learning and new assessment systems, taking into account their possible impact on undergraduate students. Twelve in-depth interviews were conducted with students and teachers. The results indicate that the use of $P B L$ is viewed with suspicion and restriction by students, while teachers believe that this methodology is a tool that aids student transformation. Both parties also have reservations relating to distance learning due to the prejudice that still exists, but they all agree that it plays a key role as a teaching aid. Teaching innovations lead to more student autonomy and multidisciplinary projects, which enable a broader view that is not limited to the discipline. Finally, it was found that the assessment systems must be reviewed by teachers, with a preference for mixed forms that take into account students' individual characteristics.

Keywords: teaching innovation; problem-based learning; distance learning; assessment systems; information technology and communication.
} 


\section{INTRODUÇÃO}

O mundo em que vivemos passa por um constante processo de mudanças, com inúmeros avanços tecnológicos que fazem com que grandes paradigmas sejam mudados frequentemente. Isto tem afetado todas as áreas do conhecimento, entre elas a educação. Uma das áreas que estão sendo beneficiadas com tais avanços é o ensino de Ciências Sociais Aplicadas e, em particular, os cursos de Administração. Estes cursos são caracterizados por contar com grande demanda e cujo conhecimento adquirido pelos alunos possui aplicação imediata nas empresas. Isto obriga os profissionais de educação a estarem constantemente atualizados com as novas descobertas de sua área, bem como fazer uso de técnicas inovadoras de ensino.

As deficiências do atual modelo de formação profissional são intensamente discutidas. Os maiores problemas encontrados vão do desinteresse e da apatia dos alunos em sala de aula até a falta de iniciativa, bem como o inadequado comportamento profissional dos egressos. Parece ser consensual que o modelo educacional convencional (por ex. aula expositiva) não é mais adequado para preparar os estudantes para sua atuação profissional no mundo atual (ESCRIVÃO FILHO; RIBEIRO, 2009).

Além do domínio do conhecimento técnico de sua área específica, seja Engenharia, Administração ou Medicina, os alunos de cursos superiores precisam adquirir um conjunto de habilidades e atitudes para complementar sua formação. Trabalhar com estas três categorias (conhecimentos, habilidades e atitudes) em sala de aula parece ser um grande desafio. Entretanto, segundo Ribeiro e Mizukami (2004), autores como Zabala (1998) acreditam que isto é viável e citam o PBL (Problem-Based Learning) como uma das possíveis abordagens.

A propagação de equipamentos de alta tecnologia (por ex. MP3 players, palmtops, celulares, notebooks, datashows e outros) ganhou força com a junção das indústrias eletrônica, de informática, de entretenimento e comunicação. Este fato, por sua vez, propiciou o desenvolvimento de novas Tecnologias de Informação e Comunicação (TIC) na sociedade e no meio educacional (NAKASHima; AmARAL, 2006). Segundo Belloni (2003), tic compreende um 
conjunto de ferramentas, suportes e canais para o tratamento e acesso à informação, os quais geram novas formas de acesso, novos modos de expressão e novos modelos de participação e recreação cultural.

As novas TICs têm aplicação conveniente na área educacional, tendo em vista que proporcionam acesso à informação de forma mais intensa do que as tecnologias anteriores. Além disso, a grande quantidade de computadores e equipamentos que já se encontram instalados nas escolas brasileiras proporcionam um ambiente favorável para o pleno uso das TICS (MARINHO, 2006).

De acordo com Masetto (2004), a educação no Brasil vem sofrendo profundas alterações, provocadas principalmente pela nova revolução tecnológica da informática e da telemática, que atingem os pilares do processo educacional e da sociedade. Deste modo, com o uso de novas TICS na sala de aula, espera-se que o estudante deixe de ser um mero sujeito do processo de aprendizagem, e o professor deixe de entregar todas as informações prontas e sistematizadas para o aluno.

Tendo em vista o cenário atual da educação em nosso país, este trabalho tem por objetivo avaliar os aspectos positivos e negativos de uma possível adoção de novas tecnologias e metodologias aplicáveis aos sistemas de ensino da Administração, tais como: PBL e EAD (Educação à distância), bem como novos sistemas de avaliação, levando em conta o impacto que as mesmas podem causar no desempenho dos alunos de graduação. 


\section{REVISÃO TEÓRICO-EMPÍRICA}

\section{INOVAÇÃO NO ENSINO}

De acordo com Lucarelli (2009), a inovação na educação é entendida como uma prática protagonista do ensino, que busca equacionar um ou vários componentes didáticos e produz uma ruptura nas práticas habituais dentro da sala de aula.

Com o objetivo de apurar quais são as práticas inovadoras de aprendizagem que possam ser aplicadas ao ensino em cursos de Administração, foram levantadas as seguintes práticas pedagógicas pautadas no trabalho de Suanno e Suanno (20I0): conhecimento prévio dos alunos; aprendizagem cooperativa; metacognição; autonomia, criticidade e criatividade; pensamento e emoção; ambientes de aprendizagem; sentipensar e escuta sensível; perguntas mediadoras; e educação por projeto de trabalho.

A Conhecimento prévio dos alunos: os autores Suanno e Suanno (2010) e Souza (2008) consideram que o processo de aprendizagem deve levar em consideração os conhecimentos anteriores dos estudantes, tendo o professor o trabalho de despertar neles a insuficiência de sua visão inicial e o seu potencial, ao criar um espaço de diálogo e relacionamento e planejar atividades que sejam enriquecidas com suas vivências anteriores, de modo a favorecer, estimular e promover o processo de construção e desconstrução do conhecimento.

B Aprendizagem cooperativa: de acordo com Souza (2008), o processo de aprendizagem é coletivo e social, no qual a aprendizagem cooperativa é uma forma inovadora para a geração de conhecimento, tendo a colaboração de todos os participantes para gerar um conhecimento mais aprofundado. Para tanto, é necessária a construção de contextos favoráveis à participação de todos (professor e estudante), bem como a valorização das realidades diversas dos participantes.

c Ambientes de aprendizagem: é importante a criação de ambientes desafiadores que sejam também acolhedores e emocionalmente saudáveis (MORAES, 2008). Estes devem facilitar os fluxos em redes energizadas pelas 
interações entre todos os participantes, trazer à tona emoções, sentimentos, desejos, intuição e imaginação que gerarão informações (sUANNO; sUANNO, 20I0).

D Metacognição: processo que busca identificar e compreender os modos de pensar, que podem potencializar o aprendizado, compreender sua intencionalidade, incentivar o diálogo e a necessidade de criar questionamentos fundamentais para os estudantes e valorizar o registro escrito da atividade mental (BRUNNER, I998; SOUZA, 2008). De acordo com Suanno e Suanno (20I0), é fundamental para o aprendizado que exista um motivo, um projeto, uma inquietação, que pode ser tanto individual quanto social.

E Autonomia, criticidade e criatividade: como uma das consequências da aprendizagem cooperativa, há o surgimento da autonomia, por meio da qual o estudante ganha a capacidade de se auto organizar, cabendo ao docente a responsabilidade de desenvolver atividades planejadas para que os estudantes se conscientizem sobre suas responsabilidades e objetivos.

F Pensamento, emoção e sentipensar: de acordo com Souza (2008), os professores universitários, de modo geral, desvalorizam o relacionamento com os estudantes, o que prejudica a interação entre os participantes da rede de conhecimento. A inovação pode ser encontrada na preocupação em criar na sala de aula um espaço agradável, acolhedor e criativo que motive os seus participantes (SUANNO; SUANNO, 20IO).

G Escuta sensível: como consequência do processo de sentipensar surge uma necessidade de criar uma escuta empática que possibilite ao indivíduo entrar em sintonia com o outro, o que acarreta em um ambiente de respeito, atenção e compreensão da fala de todos os indivíduos (BARBIER, 2002).

H Perguntas mediadoras: são perguntas significativas que auxiliam na construção de uma ponte entre a teoria e a prática, de forma a auxiliar o estudante a pensar de forma complexa (MORAES, 2008).

I Educar por projeto de trabalho: Moraes (2008) propõe que se reorganize o currículo por projetos de trabalho, em contraposição ao modo convencional de organização por disciplinas, com o intuito de trabalhar com projetos centrados em problemas. 


\section{METODOLOGIAS DE ENSINO}

\section{APRENDIZAGEM BASEADA EM PROBLEMAS}

A aprendizagem baseada em problemas - PBL (Problem-based learning) - é uma metodologia de ensino que teve sua origem em 1969 na McMaster University (Canadá) no curso de medicina. Esta abordagem é centrada no aluno, na qual se procura que este aprenda por ele mesmo. São utilizados problemas reais ou simulados, de modo a iniciar, enfocar e motivar a aprendizagem de teorias, habilidades e atitudes. A PBL é um método construtivista, ou seja, o conhecimento é construído, ao invés de ser apenas memorizado e acumulado. Tem como base resultados de pesquisas educacionais, as quais indicam que as atividades realizadas pelos alunos que são ancoradas com a vida real favorecem a aprendizagem (ESCRIVÃO FILHO; RIBEIRO, 2009). Suas principais características são a organização temática envolvendo problemas, a integração interdisciplinar entre conceitos teóricos e práticos e a ênfase no desenvolvimento cognitivo. Com isso, o aluno passa a ter um papel mais ativo e terá que fazer um esforço maior de elaboração do pensamento, diferentemente da cultura de aprendizado tradicional (COSTA, 20II).

Segundo Farina (2008), a PBL pode ser considerada inovadora porque possibilita incorporar e integrar conceitos de várias atividades, tais como investigação, identificação, solução de problemas e trabalho em grupo. Além disso, fornece uma maneira de enfrentar alguns desafios, tais como ligar a formação conceitual à prática profissional, capacitando os alunos a desenvolverem a prática para a qual estão sendo preparados (RIBEIRO, 2005).

Alguns autores sugerem que nessa metodologia a aprendizagem deve ser direcionada por um problema, sendo este de fim aberto, o qual não comporta uma única solução correta. O mesmo deve ser o foco da aprendizagem, de modo a gerar a integração dos conceitos e habilidades necessárias para resolvê-lo. Este é um dos aspectos fundamentais que diferenciam a PBL de outros processos de ensino-aprendizagem (RIBEIRO; MIZUKAMI, 2004).

De acordo com Ribeiro e Mizukami (2004), a PBL normalmente é implantada em todo o curso. Entretanto, há casos em que é aplicada como 
uma estratégia educacional parcial, ou seja, em disciplinas isoladas ou em partes de disciplinas. Existe o formato híbrido dessa metodologia, no qual há um núcleo central em que os problemas são resolvidos e outras disciplinas lhe dão suporte. Há, ainda, o formato parcial, no qual uma ou mais disciplinas em PBL estão isoladas dentro de uma grade curricular tradicional. Neste modelo, os problemas são usados para organizar, iniciar e motivar a aprendizagem de determinados conteúdos, ao passo que as demais disciplinas seguem seus próprios métodos (ESCRIVÃo FILHO; RIBEIRO, 2009).

Segundo Ribeiro (2008), seja qual for o formato adotado, o problema utilizado nessa metodologia deve necessariamente apresentar algumas características, tais como: ser de fim aberto, comportando várias respostas igualmente válidas; ser relevante ao exercício profissional dos estudantes; deve ser facilmente encontrado na prática profissional. De acordo com Duch (I995), o processo usado na PBL é o seguinte:

A Os alunos são apresentados a um problema, os quais, em grupos, organizam suas ideias e conhecimentos anteriores relacionados com o mesmo, e procuram defini-lo e solucioná-lo;

в Por meio de discussão, os alunos formulam questões de aprendizagem sobre os aspectos não compreendidos a respeito do problema. Estas são registradas pelo grupo, onde os participantes são constantemente encorajados a definir o que sabem e o que não sabem;

c Os estudantes priorizam as questões de aprendizagem geradas e decidem quais perguntas serão acompanhadas por todo o grupo e quais poderão ser atribuídas aos indivíduos. São discutidos, também, quais recursos serão necessários e onde os mesmos poderão ser encontrados;

D Em reuniões posteriores, os alunos exploram as questões de aprendizagem prévias, integrando os seus novos conhecimentos para o contexto do problema. Além disso, os estudantes continuam a definir novas questões de aprendizagem à medida que progridem com o problema.

Ainda de acordo com Duch (1995), os estudantes passam a perceber que a aprendizagem é um processo contínuo e que sempre haverá novas questões 
a serem exploradas. Neste sentido, o papel do docente na PBL é o de orientar, explorar e dar suporte às iniciativas dos alunos, ou seja, não há aula expositiva e não são oferecidas soluções fáceis ou diretas.

O objetivo da PBL é que o conhecimento seja construído por meio da busca de solução dos problemas, onde habilidades e atitudes são desenvolvidas durante este processo, as quais são mais importantes do que a solução em si (RIBEIRO; MIZUKAMI, 2004; FARINA, 2008).

Segundo Ribeiro e Mizukami (2004, p.92) os objetivos educacionais da PBL são:

A A aquisição de uma base de conhecimento integrada;

B A aquisição de uma base de conhecimento estruturada ao redor de problemas reais encontrados no campo de atuação do profissional em questão;

c A aquisição de uma base de conhecimento vinculada a processos de solução destes problemas e o desenvolvimento de um processo eficaz e eficiente de solução de problemas;

D O desenvolvimento de habilidades de aprendizagem autônoma eficaz e de habilidades de trabalho em grupo.

Apesar de a PBL abordar problemas reais (ou potencialmente reais) e envolver muitas variáveis sociais e ambientais relativas a um contexto profissional real, os problemas utilizados nesta metodologia devem ser condizentes com os níveis cognitivos, motores e afetivos dos estudantes. Isto tem o intuito de desafiar ao máximo os alunos, porém, sem frustrar sua capacidade de resolvê-los. Do mesmo modo que ocorre na prática profissional, nesta metodologia os alunos não têm todas as informações relevantes nem conhecem as ações necessárias para sua solução. Isto faz os estudantes se engajarem em um processo de reflexão, definição, coleta de informações, análise e redefinição do problema, além de desenvolverem habilidades para a solução de problemas (ESCRIvão FILHO; RIBEIRO, 2009).

A metodologia de ensino-aprendizagem PBL, como qualquer outra, apresenta vantagens e desvantagens. De acordo com Barrows e Neo (2007), as vantagens são:

A Apresenta problemas em contextos próximos à realidade; 
в Oferece oportunidade para elaborar a informação aprendida durante o processo de resolução de problemas;

C É um processo ativo;

D Estimula a capacidade de tomar decisões;

E Desenvolve a tolerância para a incerteza (não há solução única para os problemas);

F Estimula naturalmente o autoaprendizado;

G Encoraja a experiência, a intuição e a motivação.

As desvantagens da PBL, segundo Barrows e Neo (2007), são:

A Possível rejeição por parte dos tutores;

B Necessidade de um bom planejamento, para não se tornar um método de ensino comum, no qual os alunos assumem postura passiva;

C Possibilidade dos estudantes reterem pouco o que foi aprendido ou usar o conhecimento de modo inapropriado, requerendo, assim, instrutores mais capacitados;

D Os casos podem ser concluídos pelos alunos antes do aprendizado da teoria técnica fundamental, o que pode prejudicar o correto desenvolvimento da estrutura do conhecimento.

\section{EDUCAÇÃO À DISTÂNCIA}

A Educação à distância (EAD) é caracterizada por uma forma de ensino que não é realizada presencialmente ou dentro de uma sala de aula, mas sim à distância. É viabilizada pelo uso das novas Tics, além de ser um dos recursos mais citados nas discussões sobre o uso de tais tecnologias (DEMO, 2005).

De acordo com Demo (2005), estudos indicam que para um curso de EAD funcionar de maneira satisfatória, são necessários cinco componentes básicos:

1. Materiais e conteúdos a serem trabalhados no curso;

2. Competências dos professores no assunto, em pedagogia e em tecnologia, tendo em vista que os mesmos operarão no meio virtual;

3. O sistema de comunicação do curso, podendo ser síncrono (permite participação colaborativa) ou assíncrono (tutoria ou aconselhamento);

4. As tecnologias que dão suporte ao curso;

5. Os métodos de avaliação, os quais devem ser rigorosos e transparentes. 
$\mathrm{O}$ autor ainda destaca que os cursos de EAD podem ser de três formas:

1 Cursos centrados na sala de aula com a web como apoio de quadro de avisos;

2 Com o aprendizado em sala e atividades extras na web;

3 Totalmente operando sobre a web.

\section{FERRAMENTAS DE SUPORTE AO ENSINO}

\section{Ambiente Virtual de Aprendizagem}

De acordo com Carvalho Neto e Takaoka (2009), há diversas nomenclaturas para os sistemas web voltados ao ensino e aprendizagem. Entre os termos mais citados, estão Learning Management System - LMs (sistema de administração de aprendizagem), Course Management System - CMs (sistema de administração de cursos), e Virtual Learning Environment-VLE (Ambiente Virtual de Aprendizagem), entre outras. Ainda segundo os autores, os LMSs se referem aos softwares que primordialmente tem como finalidade oferecer um registro eletrônico de acesso e administração do ambiente para posteriormente oferecer um conjunto de tarefas relacionadas ao ensino. Eles organizam e fornecem acesso aos serviços relacionados à educação para professores, alunos e administradores. Enquanto os LMSs foram projetados para ambientes de aprendizagem no mundo corporativo, os AVAs são sistemas online específicos para apoiar o ensino acadêmico em sala de aula.

Segundo Farina (2008), o Moodle (Modular Object-Oriented Dynamic Learning) é um software para gestão da aprendizagem e de trabalho colaborativo. Este permite a criação de cursos online, páginas de disciplinas, grupos de trabalho e comunidades de aprendizagem. Por apresentar como filosofia uma abordagem social construtivista da educação, está em constante desenvolvimento. É conhecido também por Course Management System (CMS), Learning Management System (LMS) ou ainda Virtual Learning Environment (VLE).

O Moodle é um sistema open source de gerenciamento de cursos e que se tornou muito popular entre os educadores de todo o mundo como uma ferramenta para criar sites de web dinâmicos para seus alunos. Para o funcionamento do mesmo, basta estar instalado em um servidor web, em um de seus próprios 
computadores ou numa empresa de hospedagem (MOODLE, 20II).

O projeto Moodle tem por objetivo disponibilizar aos educadores as melhores ferramentas para gerenciar e promover a aprendizagem, e há muitas maneiras utilizá-lo:

A Possui características que lhe permitem usabilidade em grande escala para centenas de milhares de estudantes. Além disso, pode ser usado para uma escola primária ou até por um entusiasta da educação;

в Diversas instituições o utilizam como plataforma para realização de cursos totalmente online;

C Os usuários podem utilizar os módulos de atividade (como fóruns, wikis e bancos de dados) para construir comunidades amplamente colaborativas de aprendizagem em torno de seu tema. Além disso, é possível utilizá-lo como um meio de fornecer conteúdo e avaliar a aprendizagem dos alunos por meio de tarefas ou testes (MOODLE, 20II).

\section{Sistemas de Avaliação}

A avaliação é um processo complexo que deve ser compreendido como um meio que mensura a aprendizagem (ALMEIDA, I992, 1997). Em qualquer que seja a metodologia de ensino adotada, não é possível avaliar o estudante por meio de um único instrumento. Quando o professor utiliza apenas um recurso de avaliação, o resultado poderá não ser confiável, pois estará restrito a um momento exclusivo (OLIVEIRA; SANTOS, 2005). De acordo com Gronlund (I979), a função do professor é gerar métodos, estratégias e materiais visando à melhoria do ensino-aprendizado, gerando uma melhor comunicação entre o professor e o estudante, o que possibilita um incremento positivo do desempenho do estudante. A seguir, são elencados os instrumentos de avaliação que podem ser combinados para gerar um resultado melhor para o processo de ensinoaprendizagem.

A Prova objetiva: fornece uma grande amostra do conhecimento visto, elimina traços pessoais dos alunos e é fácil de julgar. Entretanto, sua elaboração é difícil e demorada, além de exigir atenção por parte do estudante durante a sua aplicação. Pode ser do tipo verdadeiro ou falso, múltipla escolha, somatório ou de preenchimento de lacunas (SALINAS, 2004); 
B Prova descritiva: de acordo com Méndez (2002), esta forma provê um retrato mais apurado e confiável da situação real do aluno, e apresenta como pré-requisito fazer perguntas inteligentes que estimulem o estudante a refletir, dando a possibilidade de organizar suas ideias, opiniões, pontos de vista e conhecimentos. Entretanto, isso gera certa subjetividade de julgamento, pois não é possível criar um padrão rígido de correção (MASETTO, 200I). Deste modo, Salinas (2004) aponta a importância de se estabelecer critérios claros que serão utilizados na correção, para evitar problemas posteriores;

c Prova oral: permite avaliar a capacidade reflexiva do aluno e sua argumentação crítica. Por outro lado, fornece uma amostra muito limitada do conhecimento adquirido, o julgamento é subjetivo e imediato, podendo ser afetado por atributos pessoais de cada aluno. Além disso, deve-se procurar formular questionamentos com o mesmo nível de complexidade para todos os estudantes para que se tenha uma avaliação mais coerente e justa;

D Prova criativa ou com consulta: a possibilidade da consulta auxilia o aluno a compreender mais aprofundadamente uma situação específica, a selecionar as fontes mais adequadas para a sua solução, sendo uma nova possibilidade para aperfeiçoar o processo de ensino-aprendizagem (MASETTO, 200I). Entretanto, o professor precisa ter o cuidado para que a prova não seja apenas uma simples transcrição do material de consulta e deve orientar os alunos sobre qual tipo de material pode ser consultado. Destaca-se que não pode ser um teste surpresa, tão pouco um instrumento de coação, mas sim algo complementar às outras formas de avaliação;

E Trabalho individual ou coletivo: necessita de uma definição clara dos critérios, bem como uma explicação das fontes de pesquisa, permitindo que os estudantes expressem suas compreensões. Entretanto, os conteúdos e temas devem ser selecionados cuidadosamente, e o estudante deve ter um conhecimento anterior sobre o assunto. Com este instrumento é possível verificar a maturidade do aluno com relação ao conteúdo, além de vislumbrar o alcance dos objetivos 
propostos (SALINAS, 2004). Os trabalhos coletivos possuem uma complexidade superior, pois exige uma delimitação de conteúdo para cada componente do grupo, o que pode distorcer a avaliação. Além disso, pode caracterizar o trabalho de apenas parte do grupo, o que cria a necessidade de haver regras claras para a sua avaliação; seminário: o objetivo principal é investigar um problema ou tema com maior profundidade e sob diferentes pontos de vista que auxiliam a aprofundar o conhecimento e compreensão. São analisados criticamente os conteúdos elencados, exigindo uma interação entre os conteúdos para não se tornarem apenas um monólogo do aluno. Deste modo, é necessário que o professor gere um roteiro para o estudo, por meio do qual irá explicar os objetivos, listar ou sugerir os temas, auxiliar os alunos, recomendar uma bibliografia mínima e complementar, discutir quais serão os critérios de avaliação, preparar um cronograma de apresentação e formular questionamentos durante as apresentações para que seja possível verificar o aprendizado dos alunos;

G participação em sala: nesta forma de análise, é necessária uma observação cuidadosa e criteriosa por parte do professor, a qual deve ser contínua durante todo o período letivo. Entretanto, essas observações durante as aulas não são suficientes para uma avaliação completa. De acordo Melchior (1994), é necessário o estabelecimento de objetivos específicos claros, que determinam o que deve ser observado e com que finalidade, de modo a garantir o processo de ensino-aprendizagem. Além disso, tem como função ser um diário do que efetivamente ocorre na sala de aula;

H autoavaliação: é um processo pelo qual o próprio estudante avalia seus conhecimentos, habilidades e atitudes, e toma consciência de seus erros e acertos, suas necessidades e qual é a melhor forma de se fomentar um pensamento crítico e reflexivo (BORDENAVE; PEREIRA, I988; HAYDT, 200I).

A utilização desses instrumentos de forma intercambiada fornece uma amplitude superior de avaliação por parte do professor. 


\section{METODOLOGIA}

Quanto à natureza, o estudo possui caráter qualitativo, com o objetivo de avaliar a percepção de discentes e docentes sobre as novas tecnologias de ensino da administração (BABBIE, 2005). É do tipo descritiva, pois possibilita especificar as propriedades relevantes das categorias de análise, onde o nível e a unidade de análise são constituídos por indivíduos (MALHOTRA, 200I). O corte da pesquisa é transversal com perspectiva longitudinal, uma vez que os dados foram coletados em um único ponto no tempo (BARDIN, 2004).

Com base no referencial teórico foram geradas as categorias de análise e suas extensões:

- Aprendizado baseado em problemas

» a importância da sua adoção nos cursos de Administração;

» o impacto da sua adoção;

» as suas vantagens e desvantagens no ensino.

- Educação à distância

» a importância da sua adoção nos cursos de Administração;

» disciplinas que seriam mais propícias à sua aplicação;

» o impacto da sua aplicação;

» as principais vantagens e desvantagens da sua aplicação;

» a percepção sobre a opinião externa aos cursos.

- Inovações no ensino

» a importância dos conhecimentos prévios dos discentes no processo de aprendizagem;

» a relevância da aprendizagem cooperativa no ensino;

» a autonomia do discente no processo de aprendizado;

» a importância da reorganização dos currículos das disciplinas por projetos de trabalho e quais as que seriam mais adequadas a esta mudança.

- Sistemas de avaliação: percepção sobre os aspectos positivos e negativos da utilização dos vários tipos, englobando:

» provas objetivas, descritivas e mistas;

$»$ provas orais; 
» provas com consulta;

» autoavaliação;

» trabalhos individuais e coletivos;

» seminários;

» participação em sala de aula.

A coleta foi realizada por meio de entrevistas pessoais em profundidade, com apoio de roteiro semiestruturado e gravação em mídia eletrônica. $\mathrm{O}$ roteiro foi elaborado de acordo com as categorias de análise extraídas do referencial teórico. Segundo Duarte e Barros (2005), entrevista individual em profundidade é uma técnica qualitativa que explora um assunto, com objetivo relacionado à aprendizagem, baseada na busca de informações e percepções do entrevistado para análise e apresentação estruturada. Além disso, a utilização de entrevista semiestruturada permite criar uma estrutura para comparação das respostas e articulação dos resultados, possibilitando descrição e análise em categorias.

As entrevistas gravadas foram transcritas e analisadas por meio de técnica de análise de conteúdo, com o objetivo de identificar os elementos definidos nesta pesquisa. Esta técnica apresenta um conjunto de procedimentos sistemáticos que tem o objetivo de descrever o conteúdo de mensagens codificadas, qualitativas ou não. O recurso da gravação se faz necessário porque possibilita o registro literal e integral da entrevista, oferecendo maior segurança à fonte (BARDIN, 2004; DUARTE; BARROS, 2005).

Foram realizadas doze entrevistas em profundidade, sendo seis professores e seis alunos do curso de Administração de uma Universidade Federal da região sul do Brasil. Com base nas recomendações metodológicas de Babbie (1999) e Creswell (2003), os entrevistados ficaram à vontade para falar livremente, com o intuito de favorecer uma atmosfera informal para que as respostas fossem as mais fidedignas possíveis. 


\section{ANÁLISE DOS RESULTADOS}

As entrevistas foram divididas em quatro etapas: PBL; EAD; inovações no ensino e sistemas de avaliação. A interpretação e análise dos dados coletados foram realizadas de acordo com as categorias de análise e são apresentadas a seguir.

\section{$P B L$}

Os professores pesquisados consideram que a aprendizagem por meio da utilização de problemas reais auxilia na assimilação dos conceitos com base no momento que os aplica de forma concreta. Tendo em vista o fato de que a informação é abundante e assume diversas formas, o método PBL propicia ao aluno tornar-se protagonista de seu conhecimento.

" $\mathrm{Na}$ atual realidade, em que informação é abundante, o aluno deve ser protagonista do seu conhecimento. O aluno de Administração deve aprender a ter autonomia, gerenciar seus recursos (cognitivo, tempo, etc.) para alcançar eficácia nos processos, este, o de aprendizado." (Professor E.)

O professor deveria ser mais bem preparado para utilizar esta metodologia em sala de aula, para que pudesse aproveitar na sua amplitude o instrumento. Além disso, poderia ser criado um padrão para a sua utilização nas mais diferentes disciplinas. As grandes vantagens do método estariam na autonomia dos alunos em resolver problemas, no aumento da motivação em sala de aula, bem como na preparação dos estudantes para a realidade da prática profissional. Como desvantagens, os professores citaram a possibilidade da abstração muito generalizada dos conteúdos, pois a responsabilidade pelo aprendizado poderia ser deslocada exclusivamente para o aluno. Isto, por sua vez, poderia gerar insegurança no discente ou no docente, por ser uma abordagem diferente das mais tradicionais.

"Acho que seria bem aceita por boa parte dos alunos e seria bem conduzida por boa parte dos docentes. Todavia, acho que alguns alunos e alguns docentes poderiam encontrar alguma dificuldade em relação a essa metodologia de ensino. Seja porque não concordam com a metodologia em si ou porque não estão aptos a lidar com ela." (Professora M.) 
Também foi citada a necessidade da disponibilização de professores capazes de orientar os alunos nessa aplicação prática, para que estejam atualizados com relação às necessidades de desenvolvimento do mercado e em proximidade com as organizações.

Para parte dos alunos pesquisados, constatou-se que a implantação do PBL deve ser vista com cautela. Para os que acham esta metodologia positiva, a mesma deveria ser implantada de forma gradativa. Porém, consideram que matérias de conteúdo mais técnico como, por exemplo, estatística e matemática, não devam utilizar este método.

"Essa metodologia em específico contribui de duas formas, primeiro ao desenvolver a cognição do indivíduo para resolução de problemas e, segundo, porque o faz trabalhar em equipe, desenvolvendo soluções coletivas, não somente individuais." (Aluno R.)

Levantou-se também que, possivelmente, o rendimento do aluno seria superior com a sua utilização. Por outro lado, os entrevistados que consideram o PBL negativo baseiam-se na crença de que a maioria dos alunos de graduação não tem conhecimento suficiente para aproveitar na plenitude a ferramenta, o que levaria a uma "grande tendência ao ensino prático em detrimento do teórico" (Aluno R.). Acreditam, ainda, que o aprendizado seria prejudicado. Há um consenso entre os alunos respondentes de que um aspecto positivo seria o de desenvolver raciocínio próprio, com a ressalva de que algumas disciplinas não apresentem o mesmo nível de interesse por todos os estudantes. Observa-se, assim, que a utilização do PBL para os alunos é um tema muito controverso. A seguir, é mostrado um trecho de entrevista que sintetiza os dois posicionamentos:

"Acredito que para o desenvolvimento de habilidades e atitudes, com o objetivo de compreender os problemas organizacionais e desenvolver soluções de maneira autônoma para tratá-los, encarregando-se de buscar o embasamento teórico, tendo em vista que a disciplina é uma ciência social aplicada, pode ter espaço. No entanto, não acredito que esse espaço deva ser o dominante, já que o papel do professor em algumas disciplinas mais teóricas e de fundamentos são essenciais. Já nas disciplinas mais aplicadas, funcionalistas, gerenciais, no entanto, a aplicação dessa metodologia de aprendizagem poderia ser adotada, 
ou até mesmo alguma matéria específica poderia ser criada justamente para a aplicação dessa metodologia. Poderia ser feito nos últimos semestres, utilizando essas simulações já que o embasamento teórico dado pelas disciplinas expositivas seria base para que os alunos pudessem aprofundar nos assuntos que sentissem maiores dificuldades." (Aluno D.)

\section{EAD}

Para os professores entrevistados, a utilização da educação à distância poderia ser útil para o melhor aproveitamento do curso pelos alunos, porém é necessário cuidado com a qualidade. Sua aplicação deveria ser restrita a disciplinas teóricas e de foco conceitual, de preferência nas que não fossem do núcleo central do curso, de modo a gerar alunos mais autônomos em relação ao seu próprio aprendizado. Quanto ao seu impacto no ensino da Administração, poderia gerar um desconforto e processo de resistência, tanto por parte dos professores quanto por parte dos alunos, o que implica em estar bem estruturado e adaptado às diferentes realidades de ambos.

"O impacto, em minha opinião, seria grande, pois o EAD ainda é uma modalidade de ensino bastante questionada. É algo relativamente novo e que em alguns casos tem dado certo, já em outros, nem tanto. Acho que muito depende do aluno também. Como ele encara O EAD. O aluno precisa estar ciente que essa é uma modalidade como outra qualquer. Requer empenho e seriedade. Não significa que é mais fácil ou deve ser mais flexível porque é à distância. A flexibilidade está inerente ao formato do curso, o que se refere à flexibilidade de horários, praticamente. Todavia, deve ser um curso bem conduzido e que deve exigir do aluno dedicação e estudo. Não significa que tem que ser mais simples ou ter menos atividades porque é um curso a distância, por exemplo. Por outro lado, o docente também precisa estar ciente do seu papel e da importância da sua 'presença' no andamento das disciplinas." (Professora L.)

A respeito de suas vantagens, foi citado o fato de prover autonomia para que os estudantes se tornem protagonistas em seu próprio aprendizado, além de ampliar a oferta de disciplinas para um público maior. Em contrapartida, para os docentes, as desvantagens encontram-se na dificuldade em avaliar a 
dedicação do aluno, além de possíveis prejuízos na qualidade e processos de aprendizagem. Sobre a situação do mercado, os professores entrevistados foram incisivos em afirmar que, pelo menos no momento atual, acreditam que os empregadores ainda sejam preconceituosos com o aluno formado inteiramente pelo formato da educação à distância.

“Toda mudança gera desconforto e resistência, isso é fato. Porém, se a modalidade de EAD for bem estruturada, bem pensada e adaptada às diferentes realidades do docente e do aluno, o resultado pode ser bem positivo. Eu fui tutora do EAD da UFPR em Administração Pública e sou professora em uma instituição na modalidade EAD. Vejo que muitas vezes o curso tem potencial para ser bom, o problema é a forma como ele é configurado. Elaborar material de apoio é importante, mas deixa o conteúdo muito restrito e sabemos que o aluno irá ler apenas o material que está ali. Então, como motivar e incentivar o aluno a ampliar o seu foco? Mas enfim, o EAD é um grande desafio, que começa pela preparação de bons profissionais para sua execução.” (Professora M.)

Entre os alunos pesquisados, levantou-se que ainda existe certo preconceito a respeito do EAD, pois acreditam que seja uma ferramenta acessória que estaria se tornando principal em alguns casos. Consideram que seria útil para o curso de Administração se a sua utilização tivesse um papel auxiliar ao ensino em sala de aula, como, por exemplo, disponibilização de material das disciplinas que pudessem colaborar com o aproveitamento melhor dos conteúdos. Entretanto, são unânimes ao discordarem do seu uso como substituto da aula presencial. Alguns consideram que as matérias instrumentais do curso poderiam, eventualmente, passar para o formato EAD, porém a forma de avaliação deve ser meticulosamente analisada para a sua aplicação.

"Acredito ser possível a utilização desta metodologia no curso de Administração, onde seria mais propícia a determinados conteúdos ou matérias que não exigissem interpretação mais complexa, seria mais bem aproveitado, o EAD, para ensino e aprendizagem de conteúdos ou matérias instrumentais. O sistema de avaliação deveria ser misto, baseado nas diversas formas de avaliação.” (Aluno R.) 


\section{INOVAÇÕES NO ENSINO}

Para os professores entrevistados, os conhecimentos e experiências anteriores dos alunos são importantes para o processo de aprendizagem. Porém, a falta de maturidade muitas vezes influencia negativamente esse processo, o que pode ser explicado pela baixa média de idade dos alunos. Quanto à aprendizagem coletiva e social, os entrevistados sugeriram que a troca de experiências e de opiniões tem um papel fundamental, pois auxiliam o futuro administrador a aprender a trabalhar em equipes. Em relação à possibilidade de se desenvolver a autonomia do aluno, sugeriram que isso seria essencial no processo de aprendizado, apesar de acreditarem que os professores em geral deveriam estar mais bem preparados para a sua implantação. A respeito da utilização do currículo por projetos, em contraposição ao modo convencional por disciplinas, sugeriram que tanto os alunos quanto os professores deveriam ser treinados para compreender as vantagens da utilização do processo. Isto poderia ser fundamental para que o aluno desenvolvesse habilidades conceituais de aplicação do conhecimento.

"Todo o processo de aprendizagem inclui a experiência prévia do aluno. A falta de maturidade muitas vezes é até uma característica que influencia no processo de aprendizagem. Acredito que o conhecimento prévio (experiência) é importante no processo de aprendizagem sim. Até pela possibilidade de entender um exemplo que o professor passa em sala. Porém, não é um fator que inviabiliza a aprendizagem, pois o amadurecimento também é um processo de aprendizagem. Acredito que a experiência prévia é necessária em disciplinas instrumentais (aplicadas) como logística, materiais, finanças, mercado de capitais e contabilidade." (Professora M.)

Os estudantes pesquisados consideram importante as experiências prévias dos alunos. Do mesmo modo, acreditam que os professores também devam ser experientes, o que seria imprescindível para um bom conteúdo das aulas, de modo a possibilitar contraposição com as experiências dos alunos, que muitas vezes não são pertinentes à disciplina. Eles consideram que a autonomia do aluno deve partir dele próprio, como, por exemplo, buscar novos conhecimentos sobre assuntos extraclasse, que possam 
colaborar com o enriquecimento da disciplina. Acreditam que os projetos multidisciplinares são positivos e possibilitam uma interação melhor entre todos os conteúdos de todas as disciplinas do curso.

\section{SISTEMAS DE AVALIAÇÃO}

De acordo com os professores entrevistados, a utilização de formas variadas de avaliação é benéfica para se medir com mais precisão o conhecimento do aluno, ao invés de utilizar-se somente de um tipo, pois a combinação pode extrair de forma mais representativa o conhecimento assimilado pelos alunos. A respeito das provas com consulta, consideram importante que se faça com que o aluno interprete determinada situação, ao invés de discorrer sobre conceitos. A autoavaliação é considerada importante para que o estudante reflita sobre o processo ensino-aprendizagem e sobre a sua dedicação em cada disciplina. Os professores também acreditam que os trabalhos individuais, em grupo e seminários, são indispensáveis para o ensino de Administração, tendo em vista que podem gerar comprometimento entre os alunos de acordo com as suas atividades em grupo. Por outro lado, ressalvam, devese tomar cuidado quanto ao tamanho dos grupos, pois equipes grandes podem permitir que os membros menos interessados contribuam muito pouco, ao passo que os mais dedicados fiquem sobrecarregados. Por fim, entendem que é fundamental a participação do aluno em sala de aula como forma de avaliação, pois auxilia em seu aprendizado, fazendo-o participar, argumentar, expor seu ponto de vista, além de poder ser utilizado para arredondar a nota.

Para os alunos pesquisados, constatou-se que a utilização de formas variadas de avaliação é positiva para obter uma melhor mensuração do conhecimento. Consideram a prova oral como uma importante forma de aprendizado, tendo em vista a realidade de mercado. Entretanto, o fato de um aluno ser mais ou menos extrovertido pode afetar sua avaliação, o que poderia gerar pressão e estresse sobre os colegas. A respeito das provas com consulta, para que tenham uma efetividade maior, acreditam que deveriam ser pautadas em mais de um referencial teórico e com um nível de dificuldade superior às sem consulta. Quanto à autoavaliação, acreditam 
que não é uma forma efetiva para se avaliar o conhecimento. De acordo com o Aluno D., “... os alunos que sabem acham que não sabem e os que não sabem precisam de nota, precisa dizer mais o que? Precisa ter muita consciência." Sobre os trabalhos individuais ou coletivos, todos os alunos pesquisados acreditam que são positivos. Ponderam que estes devem ser uma reflexão sobre o tema e não apenas uma compilação de vários textos, porém não devem ser o único instrumento de avaliação. Por fim, acreditam que avaliação da participação em sala de aula é uma forma complementar para mensurar o aprendizado, porém o professor deve ter a "capacidade de perceber as diferenças entre os alunos extrovertidos e os introvertidos." (Aluna P.)

"Do ponto de vista de facilidade de correção, as provas objetivas são as melhores, contudo de modo a captar a essência do aprendizado e não apenas o 'decoreba', provas mistas são interessantes. As vantagens são que as provas mistas captam a habilidade discursiva [descritiva] e o raciocínio e aprendizado [parte objetiva]. Aspectos negativos: Não sei se provas são a melhor forma de avaliar o aluno, visto a pressão que exercem sobre o psicológico dos mesmos, os levando muitas vezes a decorar o conteúdo e não aprendê-lo efetivamente." (Aluna M.) 


\section{CONSIDERAÇÕES FINAIS}

Segundo Korelo, Prado e Silva (2010) constata-se que rapidamente se intensificaram as pesquisas sobre as diversas possibilidades para uso das inovações na educação, destacando-se as possibilidades de uso da educação à distância (EAD), a qual é considerada como a solução dos problemas de países que ainda lutam com a falta de universalização da educação básica, como é o caso do Brasil. Autores como Demo (2005) destacam que as Tics apresentam perspectivas novas, como por exemplo, o respeito à velocidade de aprendizagem individual e a transposição de barreiras, da distância e do tempo. Para o autor, não há como escapar da tecnologia na educação, sua introdução e uso são inevitáveis e se esta não for assimilada por bem, será por mal. Acredita-se que os alunos de hoje não mostram muita motivação para a sala de aula, porém têm outros tipos de motivações ligados às novas Tics e ao uso incansável do computador.

Referente à implantação do PBL, constatou-se diferenças entre as opiniões dos alunos e dos professores entrevistados. Os alunos encontram-se divididos entre os que acham que o PBL tem impactos positivos e negativos, principalmente pelo fato de acreditarem que os estudantes são imaturos para a utilização da ferramenta, além de avaliarem que a sua utilização levaria a uma tendência do ensino prático em detrimento do teórico. Por outro lado, os professores acreditam que o pBL é um instrumento que auxilia na transformação do aluno, tornando-o protagonista e não apenas um mero espectador da construção do seu conhecimento.

A respeito da educação à distância, os alunos veem a sua utilização com maus olhos, considerando-o apenas como um instrumento auxiliar ao ensino. Por outro lado, os professores a encaram como algo benéfico, apesar de acreditarem que o processo de mudança possa gerar desconforto e um processo de resistência, tanto dos alunos quanto dos professores. Apesar de acreditarem que a EAD possa gerar autonomia para os alunos, concordam que ela não deva ser utilizada como forma única de aprendizado, substituindo as aulas presenciais. Destacam, também, que o mercado ainda é preconceituoso com o aluno formado inteiramente pelo formato da educação à distância. 
Sobre as inovações no ensino, constata-se que os alunos e os professores concordaram que as experiências prévias dos estudantes são um instrumento facilitador do aprendizado. Além disso, a autonomia do aluno em buscar novos meios para complementar o conhecimento adquirido em sala de aula, bem como os projetos multidisciplinares, possibilitam a visão do todo, de modo a não ficar restrito ao conteúdo de cada disciplina.

Observou-se, também, que tanto alunos quanto professores acreditam que a combinação de métodos diferentes de avaliação seja melhor do que a utilização de uma única forma. Entretanto, discordam no ponto referente à autoavaliação, sendo que os professores consideram como importante para que o aluno reflita sobre o próprio aprendizado, ao passo que os alunos encaram com grande desconfiança, pois consideram que a maioria dos estudantes não possui maturidade para isto.

Por fim, conclui-se que o ponto de vista dos alunos e dos professores entrevistados converge em relação à utilização de formas diferentes de avaliação e à utilização da educação à distância como forma complementar ao aprendizado. Entretanto, divergem em relação à capacidade do aluno trabalhar com maturidade e protagonismo no aprendizado, sendo que os alunos consideram que a maioria ainda é imatura para a utilização de vários instrumentos e os professores, ao contrário, acreditam que os alunos possuam esta maturidade.

Este trabalho contribui com a avaliação das percepções de alunos e professores em relação a uma eventual adoção de novas tecnologias de ensino, cujas visões indicam alguns elementos críticos que podem ajudar (ou até mesmo inviabilizar) a adoção de determinadas inovações. Tendo em vista que a abordagem qualitativa não possibilita generalizações, sugere-se a elaboração de uma pesquisa quantitativa, com o intuito de averiguar de modo mais objetivo os pontos de convergência e divergência entre discentes e docentes. Pesquisas futuras também poderiam avaliar como essas novas tecnologias poderiam melhorar o desempenho dos alunos de graduação em Administração, bem como apontar caminhos para o sucesso da adoção das inovações em tecnologias de informação e comunicação. 


\section{REFERÊNCIAS}

ALMEIDA, A. M. F. P. M. Um estudo sobre a avaliação da aprendizagem em um curso superior de ciências agronômicas. 1992. Tese de Doutorado não publicada, Faculdade de Educação, Universidade Estadual de Campinas. Campinas, SP.

ALMEIDA, A. M. F. P. M. Avaliação da aprendizagem e seus desdobramentos. Avaliação, v. 2, n. 2-4, p. 37-50, 1997.

BABBIE, E. Métodos de Pesquisa Survey. Belo Horizonte: UFMG, 2005.

BARBIER, R. Escuta sensivel na formação de profissionais de Saúde. Conferência na Escola Superior de Ciências da Saúde - FEPECS - SES-GDF. Brasília, D.F, 2002. Disponível em: $<$ http://www.barbier-rd.nom.fr/ESCUTASENSIVEL.PDF>. Acesso em: 06/08/2011.

BARROWS, H. S.; NEO, L. W. K. Principles and Practice of APBL. Singapore: Pearson Prentice Hall, 2007.

BELLONI, M. L. Educação à distância. 3.ed. Campinas, São Paulo: Autores Associados, 2003.

BRUNNER, J. Cultura da educação. Lisboa: Edições 70, 1998.

CARVALHO NETO, S.; TAKAOKA, H. Ambientes Virtuais de Aprendizagem de Código Livre como Apoio ao Ensino Presencial na Área de Ciências Sociais Aplicadas: Um Estudo de Caso em uma Instituição de Ensino Superior. In: EnANPAD, 33., 2009. São Paulo. Anais...São Paulo: Anpad, 2009.

COSTA, V. C. I. Aprendizagem baseada em problemas (PBL). Revista Távola Online. Ed. 5, mar, 2011.

CRESWELL, J. W. Research design: qualitative, quantitative and mixed methods approaches. Thousand Oaks: Sage, 2003.

DEMO, P. Éticas Multiculturais - Sobre convivência humana possível. Vozes: Petrópolis, 2005.

DUCH, B. What is problem-based learning? Disponível em: <http://www.udel.edu/pbl/cte/ jan95-what.html>. Jan 1995. Acesso em: 03/08/2011.

ESCRIVÃO FILHO, E.; RIBEIRO, L. R. C. Aprendendo com PBL - Aprendizagem Baseada em Problemas: Relato de uma experiência em cursos de engenharia da EESCUSP. Revista Minerva, v. 6, n. 1, p. 23-30, 2009.

FARINA, R. M. Contribuições do ambiente virtual de aprendizagem para o desenvolvimento de competências do engenheiro de produção utilizando o PBL. Dissertação de Mestrado em Engenharia de Produção. 2008 - Universidade de São Paulo, São Paulo.

GRONLUND, N. E. O sistema de notas na avaliação do ensino. São Paulo: Pioneira, 1979.

KORELO; J. C.; PRADO, P. H. M; SILVA, D. M. L. Escolha adoção de tecnologias de informação e comunicação na educação. Revista de Administração e Inovação, v. 7, n. 2, p. 80-103, 2010. 
LUCARELLI, E. Teoria y práctica en La universidad - La innovación en las aulas. Buenos Aires: Mino y Dávila, 2009.

MALHOTRA, N. K. Pesquisa de Marketing: Uma Orientação Aplicada. 3.ed. Porto Alegre: Bookman, 2001.

MARINHO, S. P. P. Novas tecnologias e velhos currículos; já é hora de sincronizar. Revista E-Curriculum, v.2, n.3, p. 35-38, 2006.

MASETTO, M. Atividades pedagógicas no cotidiano da sala de aula universitária: reflexões e sugestões práticas. In: Castanho, S; Castanho, M. E. (Orgs.). Temas e textos em metodologia do ensino superior. Campinas: Papirus, 2001.

MASETTO, M. Innovation in higher education. Interface-Comunicação, Saúde, Educação, v. 8, n. $14,2003 / 2004$.

MELCHIOR, M. C. Avaliação Pedagógica: função e necessidade. Porto Alegre: Mercado Aberto, 1994.

MÉNDEZ, J. M. A. Avaliar para conhecer, examinar para excluir. Porto Alegre: Artmed, 2002. MOODLE. (2011). Sobre o MOODLE. Disponível em:<http://http://moodle.org/about/>. Acesso em: 05/08/2011.

NAKASHIMA, R. H. R.; AMARAL, S. F. A Linguagem Audiovisual da Lousa Digital Interativa no Contexto Educacional. Educação Temática Digital, v.8, n.1, p. 33-50, 2006.

OLIVEIRA, K. L. de; SANTOS, A. A. A. dos. Compreensão em leitura e avaliação da aprendizagem em universitários. Psicol. Reflex. Crit., v. 18, n. 1, p. 118-124, 2005.

RIBEIRO, L. R. C.; MIZUKAMI, M. G. N. Uma Implementação da Aprendizagem Baseada em Problemas (PBL) na Pós-Graduação em Engenharia sob a Ótica dos Alunos. Semina: Ciências Sociais e Humanas, v. 25, n. 1, p. 89-102, 2004.

RIBEIRO, L. R. C. A Aprendizagem baseada em problemas (PBL): uma implementação na educação de engenharia na voz dos atores. Tese de Doutorado. 2005 - Universidade Federal de São Carlos, São Carlos.

RIBEIRO, L. R. C. Aprendizagem Baseada em Problemas - PBL: uma experiência no ensino superior. São Carlos: EDUFSCar, 2008.

SALINAS, D. Prova amanhã: entre a teoria e a realidade. Porto Alegre: Artmed, 2004.

SOUZA, C. R. de. Universidade processo de ensino aprendizagem e inovação. In: Encontro de Pesquisa em Educação da ANPED Centro-Oeste. Educação tendências e desafios de um campo em movimento, Brasília, 2008. Anais... Brasília: Anped, 2008.

EnANPAD, 33., 2009. São Paulo. Anais...São Paulo: Anpad, 2009.

SUANNO, M. V. R.; SUANNO, J. H.. Educação superior e práticas pedagógicas inovadoras: contribuições da complexidade e transdisciplinaridade. In: Congresso Internacional sobre Transdisciplinaridad, Complejidad y Ecoformación, 2010, San José Costa Rica. Anais... San José - Costa Rica, 2010.

ZABALA, A. A prática educativa: como ensinar. Porto Alegre: Artmed, 1998. 


\section{DADOS DOS AUTORES}

\section{FÁBIO PIMENTA DE PÁDUA JÚNIOR* pimentajo@gmail.com} Doutorando em Administração pela UFPR

Instituição de vinculação: Universidade Federal do Paraná

Curitiba/PR - Brasil

Áreas de interesse em pesquisa: Comportamento do Consumidor, Inovação e Emoções.

*Av. Pref. Lothario Meissner, 632, $2^{\circ}$ andar Jardim Botânico Curitiba/PR 80210-170

\section{JOÃO PEREIRA DE CASTILHO FILHO pereiracastilho@hotmail.com}

Doutorando em Administração pela UFPR

Beneficiário de auxílio financeiro do programa CAPES/REUNI.

Instituição de vinculação: Universidade Federal do Paraná

Curitiba/PR - Brasil

Áreas de interesse em pesquisa: Estratégia de Marketing, Relacionamento com

Stakeholders e Sustentabilidade.

\section{PEDRO JOSÉ STEINER NETO pedrosteiner@ufpr.br}

\section{Doutor em Administração pela USP}

Instituição de vinculação: Universidade Federal do Paraná

Curitiba/PR - Brasil

Áreas de interesse em pesquisa: Comportamento do Consumidor e Estratégia de Marketing.

\section{ZAKI AKEL SOBRINHO gabinetereitor@ufpr.br Doutor em Administração pela USP \\ Instituição de vinculação: Universidade Federal do Paraná \\ Curitiba/PR - Brasil \\ Áreas de interesse em pesquisa: Estratégia de Marketing.}

